\title{
Interactive effects of APOE and CHRNA4 on attention and white matter volume in healthy middle-aged and older adults
}

\author{
THOMAS ESPESETH \\ University of Oslo, Oslo, Norway \\ PAMELA M. GREENWOOD \\ George Mason University, Fairfax, Virginia \\ IVAR REINVANG, ANDERS M. FJELL, KRISTINE B. WALHOVD, and LARS T. WESTLYE \\ University of Oslo, Oslo, Norway \\ EIKE WEHLING and ASTRI LUNDERVOLD \\ University of Bergen, Bergen, Norway \\ HELGE ROOTWELT \\ Rikshospitalet University Hospital, Oslo, Norway \\ and \\ RAJA PARASURAMAN \\ George Mason University, Fairfax, Virginia
}

\begin{abstract}
In the present study, we investigated age-related changes in interactions between efficiency of neuronal repair mechanisms and efficiency of cholinergic neurotransmission in the context of attentional orienting. In addition, we explored white matter volume changes as possible neuronal underpinnings. A sample of 230 healthy middle-aged (53-64 years) and older (65-75 years) adults was genotyped for polymorphisms of APOE and CHRNA4, a nicotinic receptor subunit gene. Participants were administered a visuospatial attention task involving letter discrimination with location cues of varying validity. Genotype effects on white matter volume were also investigated in a subset of participants who received MRI scans. APOE interacted with CHRNA4, such that APOE- $\varepsilon 4$ carriers who were also CHRNA4 TT homozygotes showed disproportionately slowed reaction time (RT) following invalid location cues. The interaction was stronger in the middle-aged participants than in the older participants. There was also a trend for individuals with combined APOE- $\varepsilon 4 / C H R N A 4$ TT genotypes to show both lower white matter volume and slower overall RT on the attention task. The interaction of a neurotransmission gene (CHRNA4) and a susceptibility gene (APOE) suggests that the efficiency of neuronal repair mechanisms may modulate the cholinergic system to influence attentional function.
\end{abstract}

It is well known that many (but not all) perceptual and cognitive functions decline in efficiency with adult aging. For example, older adults are slower (Salthouse, 1996) and have reduced working memory capacity relative to younger adults (Dobbs \& Rule, 1989). However, the extent of age-related cognitive decline varies substantially between individuals. Some people exhibit a precipitous decline in cognitive efficiency as they age, whereas oth-

This research was supported in part by Norwegian Research Council Grant 154313/V50 to I.R. and by U.S. National Institute on Aging Grant AG19653 to R.P. The contribution from Marit Hansen Hallberg and the staff at the Department of Medical Biochemistry in the Rikshospitalet University Hospital is gratefully acknowledged. Correspondence should be addressed to R. Parasuraman, Arch Laboratory MS 3F5, George Mason University, 4400 University Dr., Fairfax, VA 22030 (e-mail: rparasur@ gmu.edu). ers show only modest losses, and a few maintain cognitive functioning at a near-constant level throughout their lives. A similar pattern is evident when one looks at the possible neural mediators of these cognitive changes $(\mathrm{Ca}-$ beza, Nyberg, \& Park, 2005). Both gray and white matter volumes shrink with age (Bartzokis et al., 2003; Resnick, Pham, Kraut, Zonderman, \& Davatzikos, 2003). However, as with cognitive decline, there is considerable individual variation (Raz et al., 2005).

What factors underlie these individual differences in brain and cognitive integrity in aging? Although many environmental modifiers of brain and cognitive aging have been identified (e.g., Bartzokis, 2004; Buckner, 2005; Raz et al., 2005), genes also play a major role. Twin studies have shown that genetic factors contribute substantially to normal variation in general cognitive ability, or $g$ (Plomin, DeFries, McClearn, \& McGuffin, 2001). The heritability 
of $g$ increases over the lifespan, reaching .62 in people over 80 years of age (McClearn et al., 1997). Although only a modest role has been observed for genetics in the rate of change in cognition with age (e.g., Christensen, Gaist, Vaupel, \& McGue, 2002), both high $g$ (Schmand et al., 1997; Whalley et al., 2000) and high cognitive functioning (Snowdon et al., 1996) early in life protect against Alzheimer's disease (AD) late in life. The high heritability of $g$ compellingly suggests that genetics must also play a role in the variation between individuals in the extent of age-related changes in cognitive function. In the present study, we examined APOE, an AD susceptibility gene with wide-ranging functions including neuronal repair, and CHRNA4, a nicotinic receptor subunit gene. We specifically tested whether these two genes interact in modulating the efficiency of attentional orienting. In addition, we conducted an exploratory analysis to identify the neurophysiological vehicle by which genes exert their effect on cognition.

\section{APOE: An AD Susceptibility or Neuronal Repair Gene?}

What genes are important in modulating cognitive function in adulthood? Several researchers have used allelic association methods to address this question (see Greenwood \& Parasuraman, 2003, for a review). One of the most widely studied is the APOE gene. APOE is the major susceptibility gene for late-onset AD (Corder et al., 1993). In fact, despite intense investigation of several other genes, APOE remains the only replicable genetic marker that has consistently been found to be associated with the disease (Tanzi \& Bertram, 2005). The APOE gene has three alleles: $\varepsilon 2, \varepsilon 3$, and $\varepsilon 4$. Inheritance of $\varepsilon 4$ is associated with increased risk of $\mathrm{AD}$ in a gene dose dependent manner (Corder et al., 1993). However, it is possible that APOE may be more appropriately characterized as a gene involved in neuronal plasticity and repair rather than only as an AD susceptibility gene (Greenwood \& Parasuraman, 2003; Teter et al., 2002). The three APOE alleles produce three isoforms of a protein that delivers lipids to neurons in the service of synaptogenesis (Mauch et al., 2001). In animals, the $\varepsilon 4$ allele has been associated with impaired repair mechanisms following lesions (Teter et al., 2002). In humans, the APOE- $\varepsilon 4$ allele is associated with reduced brain integrity following many kinds of neural insult - for example, with poorer prognosis in multiple sclerosis (Fazekas et al., 2001) and recovery following head injury (Sundstrom et al., 2004). Moreover, APOE- $\varepsilon 4$ is associated with reduction in cerebral glucose metabolism (Reiman et al., 1996) and cognitive functioning in healthy middle-aged adults (Flory, Manuck, Ferrell, Ryan, \& Muldoon, 2000; Greenwood, Sunderland, Friz, \& Parasuraman, 2000). Reiman et al. (2004) also reported an association between APOE- $\varepsilon 4$ and regional patterns of reduction in cerebral glucose metabolism in healthy volunteers who were in their 20 s and 30 s. Thus, neural and cognitive changes are seen in healthy adults less likely to develop $\mathrm{AD}$ and are seen years before $\mathrm{AD}$ diagnosis in the subset of APOE- $\varepsilon 4$ carriers who are statistically likely to develop the disease (Teter \& Finch, 2004). All these lines of evidence suggest that the effects of APOE genotype on brain and cognitive integrity are broad, early, but enduring and are not limited to AD.

Consistent with a role for APOE in neuronal protection and synaptogenesis is the growing literature showing that APOE modulates a range of cognitive processes, including visuospatial attention (Greenwood, Lambert, Sunderland, \& Parasuraman, 2005; Greenwood et al., 2000; Parasuraman, Greenwood, \& Sunderland, 2002), working memory (Greenwood, Lambert, et al., 2005; Rosen, Bergeson, Putnam, Harwell, \& Sunderland, 2002), episodic memory (Bondi, Salmon, Galasko, Thomas, \& Thal, 1999; Bondi et al., 1995), and prospective memory (Driscoll, McDaniel, \& Guynn, 2005). Furthermore, effects of APOE may be modulated by age. In a meta-analysis of studies limited to normal aging populations, Small, Rosnick, Fratiglioni, and Bäckman (2004) found that the effect size for $\varepsilon 4$ on psychometric functions such as general cognitive ability and episodic memory was maximal for middle-aged groups and declined with age thereafter. This suggests that a simple model of progressive decline due to impaired neuronal repair mechanisms does not capture the complexity of the APOE- $\varepsilon 4-\operatorname{cognition}$ relation in normal aging. But despite its pervasive influence, APOE is clearly not the whole story as far as the genetics of cognitive aging is concerned, since, for example, only about $50 \%$ of APOE- $\varepsilon 4$ homozygotes develop AD. Other genes must also be investigated - particularly those that have effects on different neurotransmitter systems.

\section{CHRNA4: A Nicotinic Receptor Gene}

The basal forebrain cholinergic system is a particularly relevant source of genetic influence due to its known vulnerability to healthy cognitive aging (Bartus, Dean, Beer, \& Lippa, 1982; Sarter \& Bruno, 2004). Muscarinic and nicotinic cholinergic receptors modulate neuronal function in the hippocampus and parietal cortex (Xiang, Huguenard, \& Prince, 1998), but the nicotinic receptor (nAChR) is especially important in regulating fast synaptic transmission (Alkondon, Pereira, Eisenberg, \& Albuquerque, 2000) and is predominantly expressed in the parietal cortex (Mentis et al., 2001). The parietal cortex is an important cortical focus of a distributed neural network of brain regions controlling different aspects of visuospatial attention (Corbetta, Kincade, Ollinger, McAvoy, \& Shulman, 2000; Posner \& Petersen, 1990). These facts may underlie the important role nicotinic receptors play in attention (Levin \& Simon, 1998; Nordberg, 2001). There is no direct evidence linking acetylcholine receptor function to cerebral volume changes. However, it is known that vascular small vessel perfusion is an important factor in inducing white matter abnormalities (O'Brien et al., 2003). Cerebral blood vessels are innervated by the cholinergic system, and both muscarinic and nicotinic receptors may play a role in regulating vasodilative capacity (Sarter \& Bruno, 2004). It is thus possible that white matter integrity may be affected by variation in nicotinic receptor function by way of a vascular mechanism. 
Relative to APOE, much less is known about the effects of genetic variation within the cholinergic system. Recently, however, polymorphisms of the nAChR subunit genes CHRNA4 and CHRNA7 have been associated with modulation of different aspects of attention (Freedman et al., 1997; Greenwood, Fossella, \& Parasuraman, 2005; Parasuraman, Greenwood, Kumar, \& Fossella, 2005). Nicotinic receptors are composed of subunits that together form the receptor itself, with the alpha-4/beta-2 receptor being the most common (Flores, DeCamp, Kilo, Rogers, \& Hargreaves, 1996) and apparently the most vulnerable to loss in both aging (Rogers, Gahring, Collins, \& Marks, 1998) and AD (Martin-Ruiz et al., 1999). CHRNA4, the gene coding for the alpha-4 subunit (Steinlein et al., 1997), was recently associated with individual variation in visuospatial attention (Parasuraman et al., 2005). Healthy adults (mean age $=35$ years) were tested for a T-to-C polymorphism in this gene and administered visuospatial attention and working memory tasks. The gene dose of the $\mathrm{T}$ allele $(0,1$, or 2) was associated with larger costs of invalid cuing in a letter-discrimination task, a version of the Posner (1980) orienting task. On the other hand, a higher dose of $\mathrm{C}$ alleles was associated with larger benefits from valid cuing. In contrast, this CHRNA4 polymorphism was not related to performance on the working memory task.

\section{Interaction of APOE and CHRNA4}

Joint examination of APOE and CHRNA4 could provide a view into the potential interaction of neurotrophic and neurotransmitter systems in the brain. There is already some preliminary evidence relevant to this issue. For example, allelic variation in APOE may alter cholinergic function. Dubelaar et al. (2004) reported that a smaller Golgi apparatus was seen in the cholinergic cells of APOE- $\varepsilon 4$ carriers in the basal forebrain nucleus basalis of Meynert, indicating lower neuronal metabolism. Cohen et al. (2003) showed that APOE- $\varepsilon 4$ was associated with higher distribution volumes of the muscarinic- 2 receptor, probably due to lower availability of acetylcholine in the synapse. Furthermore, the central synthesis of acetylcholine is dependent on local availability of lipids, which in turn depends on the integrity of the APOE-controlled delivery system for lipids (Poirier, 2000). In addition, APOEderived peptides directly inhibit nicotinic receptors (Klein $\&$ Yakel, 2004). Thus, APOE may influence the synthesis of acetylcholine, the metabolism in cholinergic neurons, the availability of acetylcholine in the synapse, and the affinity of cholinergic receptors. All of these sources of evidence point toward the need for examining the joint effects of APOE and CHRNA4 on cognitive and neural integrity in adulthood.

Even though APOE and CHRNA4 code for very different proteins with different neurobiological mechanisms and levels of specificity, there may be considerable overlap in their effects at the functional level. APOE is related to cerebral glucose hypometabolism in parietal cortex, to dysfunction in the basal forebrain cholinergic system, and to deficits in visuospatial attention. This aspect of selec- tive attention is dependent on cholinergic neurotransmission in the parietal areas, as indicated by a broad range of lesion, pharmacological, and brain imaging studies in both animals and humans (Bentley, Husain, \& Dolan, 2004; Davidson \& Marrocco, 2000; Levy, Parasuraman, Greenwood, Dukoff, \& Sunderland, 2000; Phillips, McAlonan, Robb, \& Brown, 2000; Thiel, Zilles, \& Fink, 2005; Voytko et al., 1994; Witte, Davidson, \& Marrocco, 1997). CHRNA4 codes for a cholinergic receptor that is richly expressed in human parietal cortex and has also been shown to modulate visuospatial attention (Parasuraman et al., 2005). Thus, APOE and CHRNA4 exert influences on the same (1) neuroanatomical area (parietal cortex), (2) neurochemical system (acetylcholine), and (3) cognitive phenotype (visuospatial attention). The cholinergic system is also known to be intimately linked to cognitive aging (Bartus et al., 1982). Given this "cholinergic hypothesis" of aging (which in our opinion and those of others-e.g., Sarter \& Bruno, 2004-remains viable despite criticism), we hypothesized that normal variation in the efficiency of cholinergic neurotransmission would also modulate the effect of age on cognition, perhaps by potentiating the general detrimental effect of the APOE$\varepsilon 4$ allele on cognitive integrity.

\section{The Present Study}

In the present study, we genotyped a sample of healthy middle-aged and older adults for both APOE and CHRNA4 genes and examined the independent and interactive effects of these genes on visuospatial attention. We also examined effects on total cortical and white matter volume in a smaller sample of participants who received MRI scans. We hypothesized that normal variation in a cholinergic gene (CHRNA4) would affect individual differences in attention either alone or in combination with APOE. We previously reported that a common polymorphism in the gene controlling a nicotinic cholinergic receptor, CHRNA4, modulates visuospatial attention but not working memory (Parasuraman et al., 2005). We hypothesized that the presumed variation in receptor efficiency related to the CHRNA4 polymorphism could affect cognition in an age-dependent manner, perhaps because greater receptor affinity for acetylcholine would delay the consequences of cholinergic dysfunction. In addition, in an initial exploratory analysis, we examined the effects of APOE and CHRNA4 on brain volumetric measures. We chose to focus mainly on white matter volume, given MRI evidence that there are marked white matter alterations in older adults, with the reduction being more severe in $\mathrm{AD}$ patients (Bartzokis et al., 2003). A "white matter hypothesis" of aging would predict the commonly observed loss of processing speed due to the increased instability of cortical circuits with myelin loss. Thus, functions demanding complex integration of anatomically distributed systems, such as attention, may be more vulnerable. An additional rationale is that both APOE and cholinergic neurotransmission may contribute to white matter integrity, the latter by modulating microvascular function (Sarter \& Bruno, 2004). 
Accordingly, in the present study, we tested the hypothesis that APOE and CHRNA4 genotypes have interactive effects on visuospatial attention in an age-dependent manner and in a pattern suggested by previous independent studies of these genes. We also examined in a subsample of participants the hypothesis that APOE and CHRNA4 modulate the relation of age to white matter volume. This also allowed a test of the further hypothesis that white matter volume mediates the relation of the previous variables to measures of processing speed and attention. Finally, in view of significant variations in APOE allele frequencies between populations and greater frequency of APOE- $\varepsilon 4$ in Northern Europeans (Gerdes, 2003), the use of a Norwegian sample in the present study allowed us to examine the generality and replicability of our previous studies examining gene effects on attention, which used samples from the United States.

\section{METHOD}

\section{Participants}

A total of 230 middle-aged (53-64 years, $n=110)$ and older (65-75 years, $n=120)$ people participated. They were recruited through advertisements in local newspapers. All participants were interviewed and probed for previous or present neurological or psychiatric diseases known to affect the central nervous system and for history of substance abuse. Any person with a history of treatment for any of the above was excluded from further participation. All participants gave their informed consent to their participation, including blood sample, DNA extraction and genotyping, and storage of remaining blood for up to 10 years in a "biobank" according to Norwegian regulations. The project was approved by the Regional Committee for Research Ethics of Southern Norway, and the biobank was approved by the Department of Health.

The participants were given Vocabulary and Matrices subtests of the Norwegian version of the Wechsler Abbreviated Scale of Intelligence (WASI; Wechsler, 1999), which estimates general cognitive abilities. All participants included in the study performed equal to or above an estimated full-scale IQ of 89 , with mean score more than 1 standard deviation $(S D)$ above population mean. The participants also performed the California Verbal Learning Test II (CVLT-II) as a measure of memory function (Delis, Kramer, Kaplan, \& Ober, 2000). Table 1 summarizes the participants' demographic and neuropsychological characteristics, given separately for the four genotype groups representing the combination of the APOE ( $\varepsilon 4$ present or absent) and CHRNA4 (T allele homozygote [TT +$]$ or not [TT -$]$ ) genotypes.
There were no sex, IQ, or memory score differences between genotype groups. $T$ scores on CVLT-II verified that all within-group mean $T$ scores were 50 or above with $S D$ s around 10 , which is the definition of a normal sample. Notably, $T$ scores on CVLT-II were clearly higher than 50 , consistent with the groups' high IQ scores. Thus, the measures most pertinent for diagnosing dementia or preclinical dementia indicated a normal sample. The participants also performed a wider selection of neuropsychological tests as part of another study, and the results will be reported elsewhere. The full neuropsychological protocols were examined by a clinical neuropsychologist experienced with assessments of dementia, and 1 participant was excluded from the study. Thus, not only was the sample nondemented, it is highly unlikely that many participants were in early phase dementia.

A sample of 97 participants (46-75 years of age) underwent structural MRIs. They included 85 from the larger sample and 12 younger participants in the age range 46-52 years. These people underwent the same screening procedures as the larger group. The group performed additional neuropsychological tests of attention and speed (see Table 2 for selection; and see Spreen \& Strauss, 1998, for descriptions of the tests). Informed consent was obtained.

\section{Stimuli and Apparatus}

A cued visual discrimination task developed by Parasuraman, Greenwood, Haxby, and Grady (1992), based on the Posner (1980) cued detection task, was used. Stimuli consisted of a fixation cross $\left(0.45^{\circ} \times 0.45^{\circ}\right)$, presented centrally on the computer screen. Arrow cues $\left(1.35^{\circ} \times 0.8^{\circ}\right)$ pointing left, right, or in both directions were also presented centrally. Target vowels (A, E, or U) or consonants $\left(\mathrm{D}, \mathrm{R}\right.$, or T) $\left(0.8^{\circ} \times 1.0^{\circ}\right.$, font Tahoma Bold $)$ were presented $6.7^{\circ}$ left or right of the fixation cross. All stimuli were printed in black on a uniform white background. Stimuli were presented on an EIZO 21-in. monitor, and the experimental paradigm was controlled and responses collected by the E-Prime software (Schneider, Eschman, \& Zuccolotto, 2002a, 2002b). The participants responded by pressing the appropriate key on the E-Prime compatible response box. Four cue conditions (valid, invalid, neutral, and no cue) were used. Note that the no-cue condition represented a revision of the original threecue task used in our previous research on APOE (Greenwood et al., 2000) and CHRNA4 (Parasuraman et al., 2005) and was used to examine alerting effects, which are reported elsewhere. The cue conditions were presented at four cue-target stimulus onset asynchronies $(200,500,800$, and 2,000 msec), varied within blocks of trials. Each block of 96 trials consisted of 48 valid trials (50\%) and 16 trials each for the invalid-, neutral-, and no-cue conditions $(16.67 \%$ each). There were five experimental blocks, resulting in 480 trials in total. The participants completed a 36-trial practice block with the same trial type distribution before the experiment started. Half of the targets were presented to the left of fixation and half to the right of fixation, and vowels and consonants had the same probability of

Table 1

Group Demographic Characteristics and Means and Standard Deviations of Estimated Full-Scale IQ (WASI) and T Scores on California Verbal Learning Test (CVLT)

\begin{tabular}{|c|c|c|c|c|c|c|c|c|c|c|c|c|c|}
\hline \multirow[b]{3}{*}{ Variable } & \multicolumn{12}{|c|}{ Genotype } & \multirow[b]{3}{*}{$p^{*}$} \\
\hline & \multicolumn{3}{|c|}{$\varepsilon 4-, \mathrm{TT}+$} & \multicolumn{3}{|c|}{$\varepsilon 4-, \mathrm{TT}-$} & \multicolumn{3}{|c|}{$\varepsilon 4+, \mathrm{TT}+$} & \multicolumn{3}{|c|}{$\varepsilon 4+, \mathrm{TT}-$} & \\
\hline & $n$ & $M$ & $S D$ & $n$ & $M$ & $S D$ & $n$ & $M$ & $S D$ & $n$ & $M$ & $S D$ & \\
\hline Participants $(N=230)$ & 42 & & & 103 & & & 33 & & & 52 & & & \\
\hline Male/female & $13 / 29$ & & & $27 / 76$ & & & $8 / 25$ & & & $19 / 33$ & & & .53 \\
\hline Age & & 64.4 & 6.2 & & 64.1 & 6.4 & & 65.5 & 6.3 & & 64.1 & 6.1 & .71 \\
\hline Education & & 13.9 & 3.0 & & 14.0 & 3.1 & & 13.7 & 3.2 & & 13.7 & 3.0 & .96 \\
\hline WASI & & 118.1 & 12.1 & & 117.8 & 11.1 & & 119.0 & 11.8 & & 119.3 & 12.5 & .87 \\
\hline CVLT 1-5 total & & 56.7 & 9.2 & & 57.5 & 9.3 & & 59.1 & 11.5 & & 59.5 & 12.2 & .48 \\
\hline CVLT long delay & & 55.8 & 7.7 & & 55.7 & 8.8 & & 57.3 & 10.3 & & 58.0 & 8.4 & .44 \\
\hline
\end{tabular}

Note-WASI, Wechsler Abbreviated Scale of Intelligence (Wechsler, 1999); CVLT, California Verbal Learning Test-II; CVLT 1-5 total, total score on Trials 1-5; CVLT long delay, score on 30-min delay recall. *Based on separate one-way ANOVAs with genotype as a betweenparticipants factor. 
Table 2

Group Demographic Characteristics and Means and Standard Deviations of Estimated Full-Scale IQ (WASI) and Raw Scores on Selected Neuropsychological Tests

\begin{tabular}{|c|c|c|c|c|c|c|c|c|c|c|c|c|}
\hline \multirow[b]{3}{*}{ Variable } & \multicolumn{12}{|c|}{ Genotype } \\
\hline & \multicolumn{3}{|c|}{$\varepsilon 4-, \mathrm{TT}+$} & \multicolumn{3}{|c|}{$\varepsilon 4-, \mathrm{TT}-$} & \multicolumn{3}{|c|}{$\varepsilon 4+, \mathrm{TT}+$} & \multicolumn{3}{|c|}{$\varepsilon 4+, \mathrm{TT}-$} \\
\hline & $n$ & $M$ & $S D$ & $n$ & $M$ & $S D$ & $n$ & $M$ & $S D$ & $n$ & $M$ & $S D$ \\
\hline Participants $(N=97)$ & 18 & & & 42 & & & 15 & & & 22 & & \\
\hline Male/female & $7 / 11$ & & & $10 / 32$ & & & $2 / 13$ & & & $8 / 14$ & & \\
\hline Age & & 62.3 & 9.1 & & 66.1 & 6.8 & & 65.6 & 7.8 & & 62.8 & 8.0 \\
\hline Education & & 14.3 & 3.1 & & 14.0 & 3.0 & & 12.7 & 2.8 & & 14.1 & 2.6 \\
\hline WASI & & 117.4 & 13.6 & & 118.1 & 9.7 & & 117.7 & 13.6 & & 122.3 & 11.7 \\
\hline Stroop CW & & 60.7 & 16.2 & & 56.9 & 9.8 & & 67.0 & 23.0 & & 55.9 & 11.9 \\
\hline TMT A & & 36.1 & 11.7 & & 36.7 & 12.7 & & 37.7 & 14.0 & & 36.1 & 9.9 \\
\hline TMT B & & 91.3 & 34.0 & & 80.6 & 25.4 & & 85.6 & 38.3 & & 75.8 & 20.0 \\
\hline Digit-symbol & & 51.5 & 13.0 & & 49.1 & 9.8 & & 45.8 & 12.2 & & 52.2 & 11.3 \\
\hline CVLT $1-5$ total & & 50.3 & 9.8 & & 52.0 & 9.0 & & 50.7 & 10.4 & & 57.2 & 14.9 \\
\hline CVLT long delay & & 12.1 & 2.0 & & 11.9 & 2.8 & & 12.7 & 3.3 & & 13.2 & 2.7 \\
\hline
\end{tabular}

Note-WASI, Wechsler Abbreviated Scale of Intelligence (Wechsler, 1999); Stroop CW, Stroop color-word conflict; TMT A and B, Trail Making Test Parts A and B, respectively; Digit-symbol, from the revised Wechsler Adult Intelligence Scale; CVLT 1-5 total, total score on Trials 1-5; CVLT long delay, score on 30-min delay recall.

presentation. Intertrial interval varied between $2,200,2,500$, and $2,800 \mathrm{msec}$ and was counterbalanced between trial types.

\section{Procedure}

The participants were seated in front of the computer monitor after finishing the informed consent and neuropsychological test procedures. Each trial began with a fixation cross presented centrally on the computer monitor for $500 \mathrm{msec}$. Following the disappearance of the fixation cross, an arrow cue was presented over the same spatial area. After a variable SOA, the target letter was presented to the left or right of the cue. The cue and target letter remained on the screen until response or until 2,000 msec had elapsed. The participants were instructed to respond by pressing the leftmost key on the response box with the left index finger as fast and accurately as possible if the letter was a vowel or by pressing the rightmost key with the right index finger if the letter was a consonant. If the response was correct, the participants were notified by the presentation of the word RIKTIG ("correct") for $1,000 \mathrm{msec}$ about $4^{\circ}$ above the center of the screen. After the variable ITI, the next trial began. The participants were given a short break between blocks. There was a longer break between Blocks 2 and 3, in which the participants worked with other tasks.

\section{DNA Extraction and Genotyping}

Genotyping was performed by real-time PCR with allele-specific fluorescence energy transfer probes and melting curve analyses on the LightCycler system (Roche Diagnostics, Mannheim, Germany). DNA was extracted from $300 \mu \mathrm{l}$ whole blood using MagNA Pure LC DNA Isolation Kit-Large Volume on the MagNA Pure LC (Roche), eluted and diluted to $1 \mathrm{ml}$, of which $5 \mu \mathrm{l}$ was applied in each assay.

Typing of the APOE- $\varepsilon 2,-\varepsilon 3$, and $-\varepsilon 4$ genotypes was performed using the LightCycler APOE Mutation Detection Kit (Roche). The assay was performed as specified by the supplier, except for scaling down the total assay volume from 20 to $10 \mu$ l. The laboratory participates in an external quality assurance program (Equalis, Uppsala, Sweden) that includes APOE genotyping.

For typing of the T 1545C polymorphism of the CHRNA4 gene, primers and probes were designed using the LightCycler Probe Design Software 2.0 (Roche) and Oligo 6.70 (Molecular Biology Insights, Inc., Cascade, $\mathrm{CO}$ ) and checked for unspecific priming using www.ncbi.nlm.nih.gov/BLAST/. Primers TCTCGCAACACCCACTC (sense) and CCTTCAGGTGGTCTGCAAT (antisense) amplify $205 \mathrm{bp}$. The sensor probe, CGAGCGCCACGGTCAfluorescein, identifies the $1545 \mathrm{C}$ allele (underlined). The anchor probe used was LC640-GACCCGCAGCACCAAAGC-phosphate. All primers and probes were synthesized by TIB MOLBIOL (Berlin). PCR was performed in a $20-\mu 1$ reaction volume containing genomic DNA (see above), $0.2 \mu \mathrm{M}$ sense primer, $0.8 \mu \mathrm{M}$ antisense primer, $0.15 \mu \mathrm{M}$ of each probe, $3.5 \mathrm{mM} \mathrm{MgCl}_{2}$, and 1x FastStart DNA Master Hybridization Probes (Roche). The PCR conditions were denaturation and activation $\left(95^{\circ} \mathrm{C}, 10 \mathrm{~min}\right) ; 37$ cycles of denaturation $\left(95^{\circ} \mathrm{C}, 5 \mathrm{sec}\right)$, annealing $\left(60^{\circ} \mathrm{C}, 10 \mathrm{sec}\right)$, and elongation $\left(72^{\circ} \mathrm{C}, 10 \mathrm{sec}\right)$; denaturation and polymerase inactivation $\left(98^{\circ} \mathrm{C}\right.$, $5 \mathrm{~min})$; and melting curve analysis $\left(40^{\circ} \mathrm{C}[60 \mathrm{sec}]\right.$ to $\left.75^{\circ} \mathrm{C}\right)$. All ramp rates were $20^{\circ} \mathrm{C} / \mathrm{sec}$, except for the melting curve analysis $\left(0.1^{\circ} \mathrm{C} /\right.$ $\mathrm{sec})$. The polymorphisms were distinguished by melting temperatures of $63^{\circ} \mathrm{C} / \mathrm{sec}(1545 \mathrm{C})$ and $52^{\circ} \mathrm{C} / \mathrm{sec}(1545 \mathrm{~T})$. Correct genotyping was verified by DNA sequencing.

Following identification of the genotypes of each participant, the total sample of 230 was subdivided into four separate genotype groups representing the combination of the APOE and CHRNA4 genotypes, as follows: (1) APOE- $\varepsilon 4$ absent, CHRNA4 TT homozygote $(\varepsilon 4-, \mathrm{TT}+)$; (2) APOE- $\varepsilon 4$ absent, CHRNA4 TC or CC $(\varepsilon 4-$, TT-); (3) APOE- $\varepsilon 4$ present, CHRNA4 TT homozygote $(\varepsilon 4+$, $\mathrm{TT}+)$; and (4) APOE- $\varepsilon 4$ present, CHRNA4 TC or CC $(\varepsilon 4+, \mathrm{TT}-)$ (see Table 1).

\section{MRI Protocol and Volumetric Analysis}

A Siemens Sonata 1.5 Tesla magnet with a conventional head coil was used. Two 3-D magnetization prepared rapid gradient echo T1weighted sequences, each $8 \mathrm{~min} 46 \mathrm{sec}$ in length, were run for all participants. Each volume consisted of 128 sagittal slices $(1.33 \times$ $1 \times 1 \mathrm{~mm}$ ), with an in-plane voxel size of $1 \mathrm{~mm}^{3}$ and were acquired with $\mathrm{TR}=2,730 \mathrm{msec}, \mathrm{TE}=3.43 \mathrm{msec}, \mathrm{TI}=1,000 \mathrm{msec}$, flip angle $=7^{\circ}$, and $256 \times 256$ matrix. The images were transformed to the DICOM format and transferred to a Linux workstation for volumetric analyses. Measures of total cortical gray and white matter volume were obtained. Cortical thickness measurements were obtained by reconstructing representations of the gray/white matter boundary (Dale, Fischl, \& Sereno, 1999; Dale \& Sereno, 1993) of the cortical surface and then calculating the distance between those surfaces. This method uses both intensity and continuity information from the entire 3-D MR volume in segmentation and deformation procedures to construct representations of cortical thickness. The maps are created using spatial intensity gradients across tissue classes and are therefore not simply reliant on absolute signal intensity. Maps were averaged across participants using a nonrigid highdimensional spherical averaging method to align cortical folding 
patterns (Fischl, Sereno, \& Dale, 1999). This procedure provides a mean measure of cortical thickness for each group at each point on the reconstructed surface, and the total cortical volume was calculated from the mean thickness maps.

\section{Data Analyses}

Responses with reaction times (RTs) lower than $200 \mathrm{msec}$ were discarded from further analyses, and 2,000 msec was the upper time limit of the response window for the visuospatial attention task. Median RTs for correct responses and mean accuracy scores were obtained for each cue condition (valid, invalid, neutral, and no cue) and each SOA condition $(200,500,800$, and 2,000 msec).

The participants were grouped by age (53-64 and 65-75 years) and the four genotype subgroups described previously $(\varepsilon 4-, \mathrm{TT}+$; $\varepsilon 4-, \mathrm{TT}-; \varepsilon 4+, \mathrm{TT}+$; and $\varepsilon 4+, \mathrm{TT}-)$. The sample size was not sufficiently large for individual genotype or allele dose grouping.

\section{RESULTS}

\section{Accuracy}

Mean accuracy rates were generally high, ranging from $97.7 \%$ to $98.9 \%$. Accuracy data were submitted to a repeated measures ANOVA with cue validity (no cue, invalid, neutral, valid) and $\operatorname{SOA}(200,500,800$, and 2,000 msec) as within-participants factors and APOE genotype $(\varepsilon 4+$ and $\varepsilon 4-$ ), CHRNA4 (TC/CC and TT) and age group (5364 and 65-75 years) as the between-participants factors. There were no main effects or interaction involving any of the between-participants factors, but there were main effects of cue validity $[F(3,666)=3.52, p=.016]$ and SOA $[F(3,666)=3.88, p=.01]$. Accuracies were highest for SOAs of 500 and $800 \mathrm{msec}$ and under valid cuing conditions.

\section{RT}

Omnibus analysis. Means of median RTs for each cell were submitted to a repeated measures ANOVA with cue validity (no cue, invalid, neutral, valid) and SOA (200,
500,800 , and 2,000 $\mathrm{msec}$ ) as within-participants factors and APOE genotype, CHRNA4 genotype, and age group as the between-participants factors. A main effect of cue validity was observed $[F(3,666)=213.06, p<.0001]$, with RTs fastest following valid cues, slowest following invalid cues, and intermediate following neutral and no-cue trials. RTs were faster for neutral trials relative to no-cue trials. As expected, the cue validity effect developed over time, as indicated by a significant main effect of SOA $[F(3,666)=77.39, p<.0001]$, and a significant cue validity $\times$ SOA interaction $[F(9,1998)=18.18, p<$ .0001 ; see Figure 1]. APOE- $\varepsilon 4$ carriers were generally slower than noncarriers [main effect of APOE genotype, $F(1,222)=7.65, p=.006]$, but a significant four-way interaction showed that the effect of APOE genotype was modulated by cue validity, CHRNA4, and age group $[F(3,666)=3.29, p=.021$; see Figure 2).

Valid and invalid RT analyses. The significant fourway interaction in the omnibus analysis justified separate ANOVAs for RTs on two levels of cue validity (valid and invalid trials), with APOE genotype, CHRNA4 genotype, and age group as between-participants factors and SOA as the within-participants factor.

Invalid RT. For RTs following invalid cues (Figure 1), there was a steady increase in RT with increasing SOA $[F(3,666)=33.26, p<.0001]$, but SOA did not interact with group factors. RTs were slower overall for APOE$\varepsilon 4$ carriers, resulting in a main effect $[F(1,222)=7.91$, $p<.005]$. Furthermore, this effect was stronger if the participant also had the CHRNA4 TT genotype ( $\mathrm{C}$ allele absent), as indicated by a significant APOE $\times$ CHRNA4 interaction $[F(1,222)=9.78, p<.02]$. This effect in turn interacted with age group, leading to a three-way interaction $[F(1,222)=5.04, p<.03]$. Figure 3 shows that invalid RT was slowest in those who were CHRNA4 TT homozygotes and APOE- $\varepsilon 4$ carriers in both age groups.

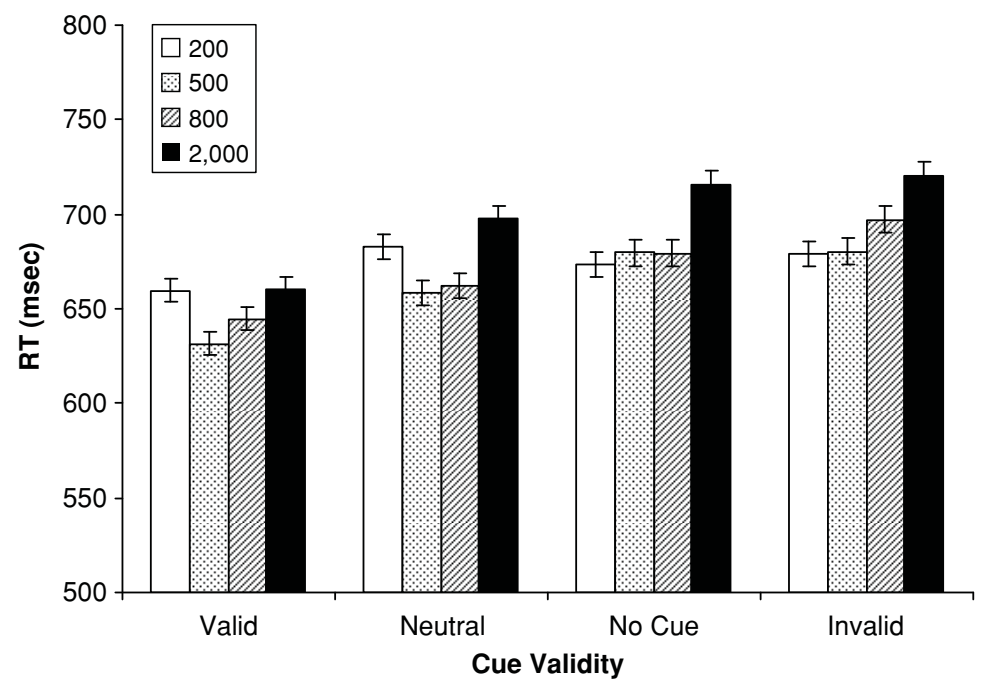

Figure 1. Reaction time (RT) data (in milliseconds) from all participants $(N=230)$, plotted as a function of cue validity and stimulus onset asynchrony (SOA). Error bars represent standard errors. 
A

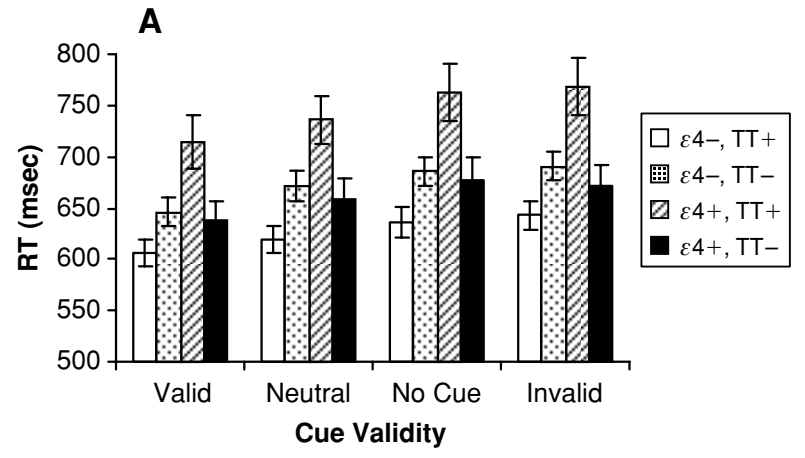

B

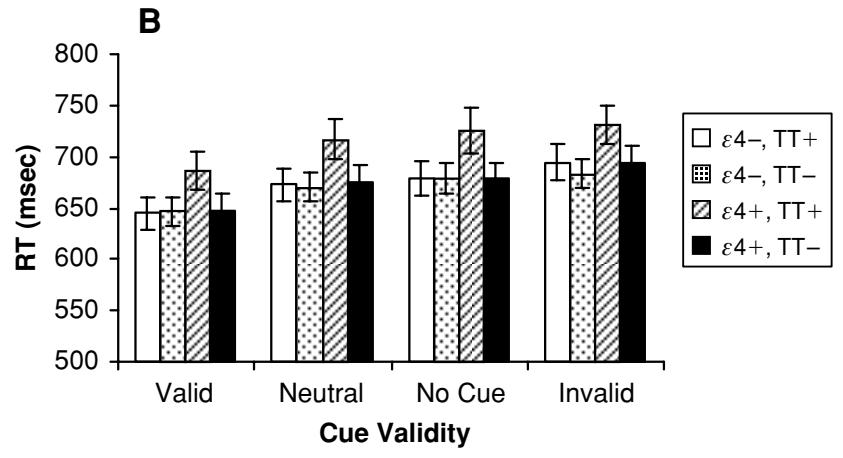

Figure 2. Reaction time (RT) data (in milliseconds) plotted as a function of cue validity, genotype group (combinations of APOE$\varepsilon 4-/ \varepsilon 4+$ and CHRNA4 TT $-/ T T+)$. (A) Age group 53-64 years $(n=110)$. (B) Age group 65-75 years $(n=120)$. Error bars represent standard errors.

However, the pattern was different for the two age groups, with the effect somewhat more marked in the 53- to 64year-old group (Figure 3A) than in the 65- to 75-year-old group (Figure 3B).

Valid RT. For RTs following valid cues, there was also a main effect of SOA $[F(3,666)=93.33, p<.0001]$. However, in contrast to the monotonic increase in RT with SOA on invalid trials, on valid trials, RTs were slower for the 200-msec SOA than for the 500- and 800-msec SOAs. APOE- $\varepsilon 4$ carriers were also generally slower on valid trials [main effect, $F(1,222)=6.32, p=.013$ ], particularly in combination with CHRNA4 TT genotype [APOE $\times$ CHRNA4, $F(1,222)=8.09, p=.005$; see Figure 4 for genotype interaction]. There was a four-way interaction of APOE $\times$ CHRNA $4 \times$ age group $\times \operatorname{SOA}[F(3,666)=$ $4.81, p=.005]$. The participants over 65 years of age were slowed on shorter SOAs (200 and $500 \mathrm{msec}$ ), as evident in the SOA $\times$ age group interaction $[F(3,666)=6.58, p<$ $.001]$. Thus, RTs were slower overall for APOE- $\varepsilon 4$ carriers, with the younger APOE- $\varepsilon 4$ carriers more slowed by the CHRNA4 TT genotype than were the older carriers, and the older participants were slower than the younger participants, particularly at short SOAs.
Derived measures of cue validity. Cue validity data are commonly analyzed in the form of derived measures of total cue validity effects (invalid - valid RT), costs of invalid cues (invalid - neutral RT), and benefits of valid cues (neutral - valid RT). Because cue validity effects for endogenous attention shifting tasks are best developed at longer SOAs (Parasuraman et al., 1992), we analyzed these derived measures at the longest SOA $(2,000 \mathrm{msec})$. Total cue validity, cost, and benefit (see Figures 5 and 6) were submitted to separate ANOVAs with APOE genotype, CHRNA4 genotype, and age group as between-participants factors.

The total cue validity effect was greater in APOE- $\varepsilon 4$ carriers than in the noncarriers, reflected in a main effect of APOE genotype $[F(1,222)=4.06, p<.05]$. Costs were greater in the APOE- $\varepsilon 4$ carriers $[F(1,222)=3.85, p<.05]$, and this effect was strongest in the CHRNA4 TT homozygotes (Figure 5), as indicated by a significant APOE $\times$ CHRNA4 $\times$ age group interaction $[F(1,222)=3.95, p<$ $.05]$ (Figure 6). Benefits showed no significant effects.

\section{Morphometry Measures}

As indicated above, the rationale for this analysis was to take an initial step toward isolating the intermediate neu-
A

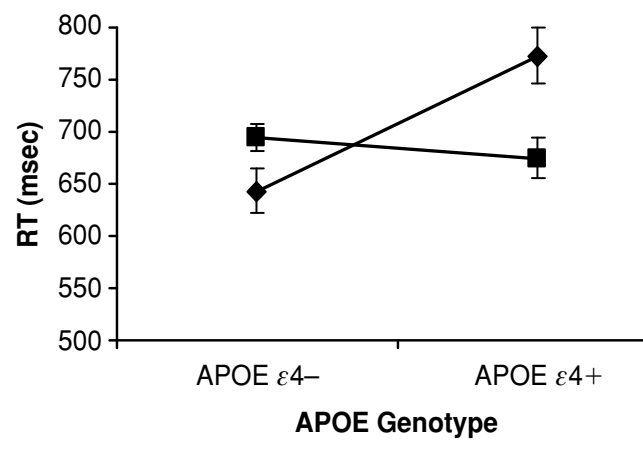

B

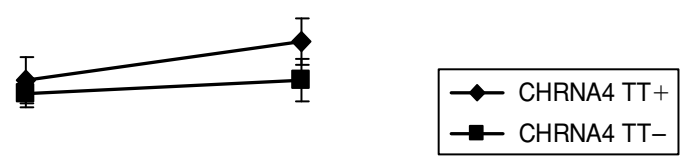

Figure 3. Reaction times (RT, in milliseconds) on trials with invalid cuing plotted as a function of APOE- $\varepsilon 4-/ \varepsilon 4+$ and CHRNA4 TT -/TT +. (A) Age group 53-64 years $(n=110)$. (B) Age group 65-75 years $(n=120)$. Error bars represent standard errors. 
A

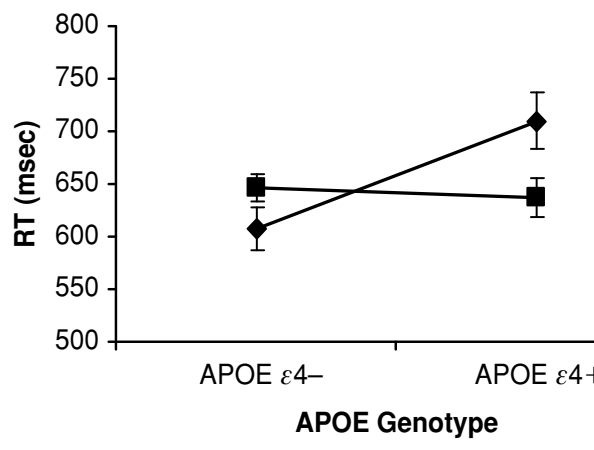

B

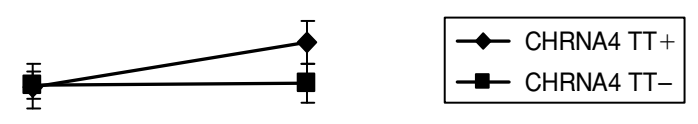

APOE $\varepsilon 4-\quad$ APOE $\varepsilon 4+$

APOE Genotype

Figure 4. Reaction times (RT, in milliseconds) on trials with valid cuing plotted as a function of APOE- $\varepsilon 4-/ \varepsilon 4+$ and CHRNA4 TT - /TT +. (A) Age group 53-64 years $(n=110)$. (B) Age group 65-75 years $(n=120)$. Error bars represent standard errors.

rophysiological mechanisms through which genes exert their effects on behavioral measures. Previous attempts to relate cognitive consequences of APOE genotype to brain structure have focused on hippocampal volume (e.g., Plassman et al., 1997) and cerebral metabolism (Reiman et al., 1996; Reiman et al., 2004). However, both of those measures could be driven by white matter integrity. Hence, we asked whether white matter volume correlated with cognitive change. We first examined performance on the visuospatial attention task in this smaller sample. An ANOVA on means of median RTs and separate ANOVAs on invalid and valid RT and on derived measures of RT cost and benefit showed a very similar pattern between this subsample and the larger group presented above. Group differences on calculated costs and benefits were about the same nominal size (i.e., $20-25 \mathrm{msec}$ ) but did not reach significance due to the lower statistical power. For this reason, and because there were insufficient data to analyze any within-participants factors, overall RT on the attention task was used as an index of cognitive function in the following analyses.

Overall RT and total white matter and cortical volume were submitted to separate ANOVAs with APOE and CHRNA4 genotype as between-participants factors. APOE- $\varepsilon 4$ carriers had slower RTs $[F(1,93)=3.95$, $p<.05$ ] and were even slower in combination with the CHRNA4 TT genotype [interaction, $F(1,93)=4.01, p<$ .05 ; see Figure 7A]. Simple effects analyses showed that APOE had no impact on RT for those with CHRNA4 TC or CC genotypes ( $p=.99)$, but that $\varepsilon 4$ carriers had significantly slower RTs if they were also CHRNA4 TT homozygotes $(p=.02)$. There was no relation between total cortical volume and genotypes, and it was not analyzed further. Analysis of white matter volume showed a marginal main effect of $\mathrm{APOE}[F(1,93)=2.71, p=.1]$, but a significant interaction between APOE and CHRNA4 $[F(1,93)=4.40, p<.04]$. Simple effects analyses revealed that APOE had no impact on white matter volume

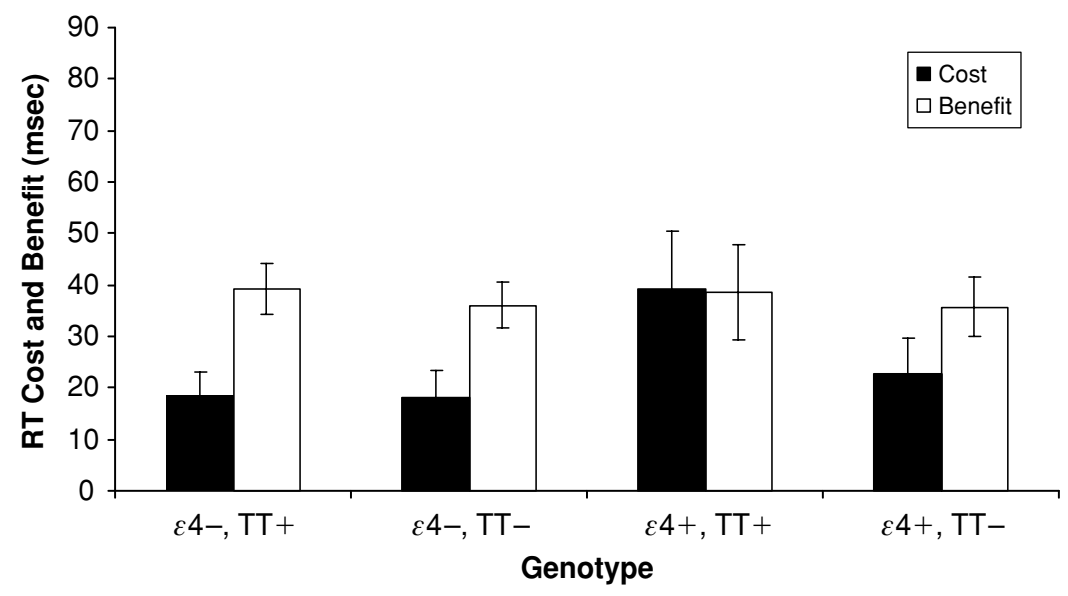

Figure 5. Calculated reaction time (RT, in milliseconds) benefits of valid cues (neutral cue RT - valid cue RT) and costs of invalid cues (invalid cue RT - neutral cue RT) plotted as a function of genotype group (combinations of APOE- $\varepsilon 4-/ \varepsilon 4+$ and CHRNA4 TT $-/ T T+)$. Total $N=230$. Error bars represent standard errors. 
A

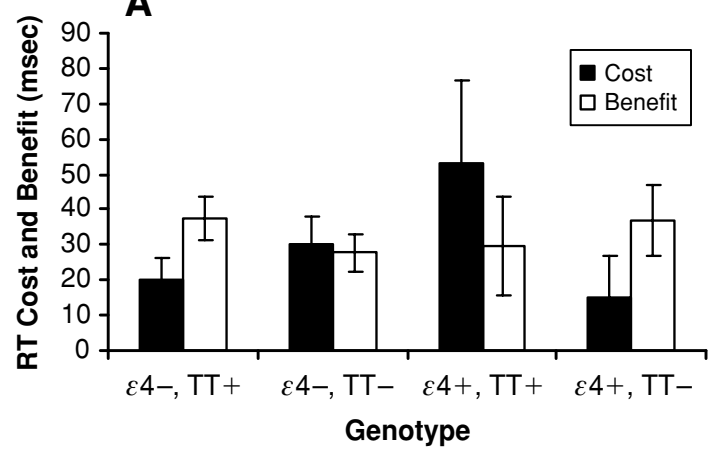

B

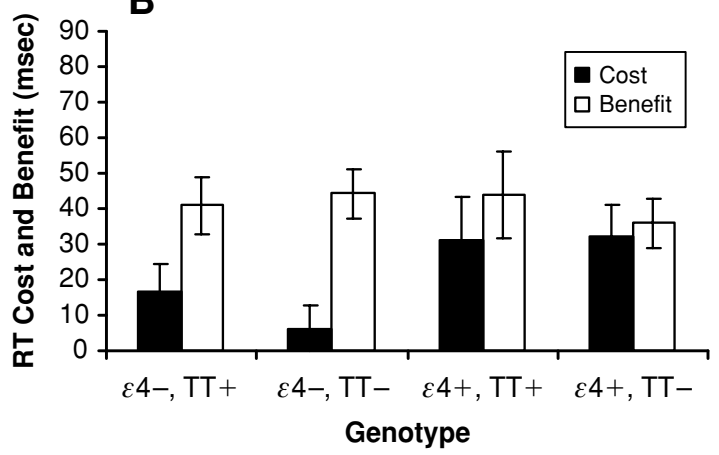

Figure 6. Calculated reaction time (RT, in milliseconds) benefits of valid cues (neutral cue RT - valid cue RT) and costs of invalid cues (invalid cue RT - neutral cue RT) plotted as a function of genotype group (combinations of APOE$\varepsilon 4-/ \varepsilon 4+$ and CHRNA4 TT-/TT +$)$. (A) Age group 53-64 years $(n=110)$. (B) Age group 65-75 years $(n=120)$. Error bars represent standard errors.

for those who were CHRNA4 heterozygotes or CC homozygotes $(p=.70)$ but that $\varepsilon 4$ carriers who were TT homozygotes had significantly reduced white matter volume $(p=.03)$. Thus, the interaction reflected lower white matter volume in the APOE- $\varepsilon 4$ carriers who were also TT homozygotes (Figure 7B), relative to the other three genotype groups.

Subsequently, we attempted to test whether genotype effects on RT are mediated specifically by white matter changes by trying to isolate effects of white matter and age on RT with an ANCOVA and partial correlation analyses. An ANCOVA with overall RT as a dependent variable, APOE and CHRNA4 genotype as fixed factors, and white matter volume as a covariate showed a main effect of white matter volume $[F(1,92)=4.05, p<.05]$, but the group differences disappeared $(p>.1)$. Thus, according to the criteria set by Baron and Kenny (1986), the effect of the APOE $\times$ CHRNA4 interaction on RT may at least in part be mediated through white matter volume.

Partial correlation analyses showed that age correlated positively with RT (zero-order correlation, $r=.22, p=$
$.03)$, but not after controlling for white matter volume (partial correlation, $r=.16, p>.1$ ). White matter volume correlated negatively with RT even when controlling for age (partial correlation, $r=-.21, p=.04$ ). Inspection of the zero-order correlation $(r=-.26)$ suggests that controlling for age only modestly interferes with the white matter volume/RT correlation. Thus, white matter volume exerts unique effects on RT. Age is significantly correlated with speed-sensitive neuropsychological measures, such as the Stroop, Trail-Making Test A and B, and digit-symbol substitution tasks. Pearson's correlations ranged from $-.41(p<.01)$ on the digit-symbol substitution task to $.25(p<.02)$ for Trail-Making Test A. However, our white matter volumetric measure did not correlate significantly with any of these neuropsychological measures $(p s>.1$ for all measures). Thus, in contrast to age, behavioral effects of white matter volume do not seem to reflect nonspecific slowing.

In summary, this shows that both the effects of APOE and the effects of the interaction between APOE and CHRNA4 on RT may at least in part be mediated through
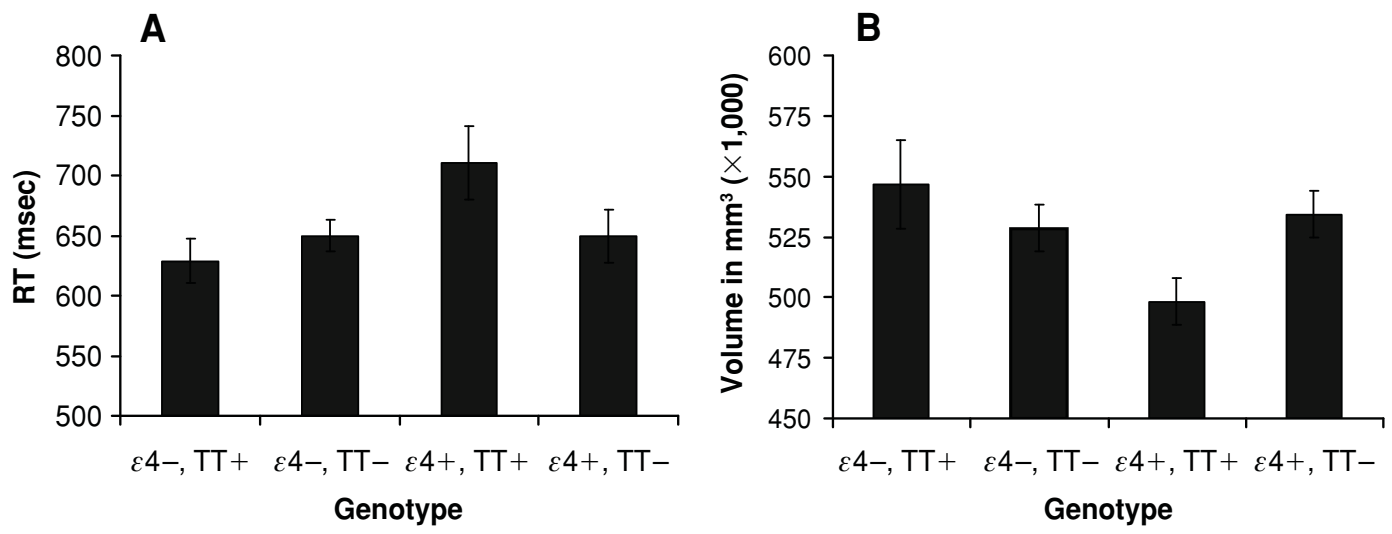

Figure 7. (A) Overall reaction times (RT, in milliseconds) on the attention task as a function of genotype group. Total $N=97$. Error bars represent standard errors. (B) Total white matter volume in cubic millimeters plotted as a function of genotype group (combinations of APOE- $\varepsilon 4-/ \varepsilon 4+$ and CHRNA4 TT $-/ T T+$ ). Total $N=97$. Error bars represent standard errors. 
white matter volume. Furthermore, this analysis indicates that the effect of APOE on overall RT was unrelated to age, whereas the APOE $\times$ CHRNA4 interaction was influenced by age.

\section{DISCUSSION}

In the present study, we examined whether the APOE and CHRNA4 genes have interactive effects on visuospatial attention in an age dependent manner, and whether these genes also influence the relation of age to total cortical and white matter volume. With respect to genetic effects on attention, the results provide a positive answer. Relative to non-APOE- $\varepsilon 4$ carriers, individuals with the APOE- $\varepsilon 4$ allele had increased RT costs of invalid cuing. This finding replicates in a Norwegian sample earlier findings obtained with a very similar endogenous visuospatial attention task in United States samples (Greenwood, Lambert, et al., 2005; Greenwood et al., 2000). More importantly, APOE interacted with the nicotinic receptor gene CHRNA4, previously shown to also influence visuospatial attention (Parasuraman et al., 2005). Specifically, in Parasuraman et al.'s study, increased gene dose of the T allele of the T1545C CHRNA4 polymorphism was associated with increased RT costs. In the present study, individuals possessing an APOE- $\varepsilon 4$ allele in combination with CHRNA4 TT genotype showed disproportionately slowed RTs following invalid location cues. In contrast, the TT genotype had the opposite effect in non-APOE- $\varepsilon 4$ carriers. Moreover, there was an age difference to this pattern. The APOE $\times$ CHRNA4 interaction was stronger in the middleaged participants than in the older participants.

These results show for the first time that the cognitive effects of a susceptibility gene (APOE) can be modulated by a neurotransmission gene (CHRNA4). These data originate from a different population with different allele distribution of APOE- $\varepsilon 4$ (Gerdes, 2003). People in northern European countries show higher frequencies of APOE- $\varepsilon 4$ alleles than do people in southern European countries and the United States. Still, epidemiological studies give no indication of differences in age-related risk of dementia between people in southern and northern European countries (Rocca et al., 1991). Thus, the results speak to the replicability and generality of the previous findings in which APOE and CHRNA4 were examined separately. More generally, the results support the view that neuronal repair mechanisms interact with neurotransmitter systems to influence cognitive function. Interactive effects of APOE and CHRNA4 on attention are interpretable given the important role of nicotinic cholinergic receptors in attention (Levin \& Simon, 1998; Nordberg, 2001) and the fact that cortical synthesis of acetylcholine is dependent on local availability of lipids, which are strongly influenced by APOE (Poirier, 2000). However, it remains for further research to determine which of several underlying mechanisms - acetylcholine synthesis (Poirer, 2000), cholinergic neuronal metabolism (Dubelaar et al., 2004), synaptic availability of acetylcholine (Cohen et al., 2003), the affinity of cholinergic receptors (Klein \& Yakel, 2004), or other factors - are responsible for the interactive effects of APOE and CHRNA4 on attention.

The genetic effects were more pronounced in the younger age group and weaker in the older group. While this pattern of findings seems counterintuitive, it is consistent with the meta-analysis by Small et al. (2004), which showed that effects of APOE genotype diminish in old age. One possible explanation is that cognitive changes affect self-selection mechanisms such that APOE- $\varepsilon 4$ carriers with subjective cognitive difficulties are effectively excluded from participation in a study on healthy aging and are more likely to be found as participants in investigations on samples with subjective memory complaints (e.g., Reinvang, Espeseth, \& Gjerstad, 2005). However, the rate of $\varepsilon 4$ carriers was equal between the two age groups in the present study. One may also speculate that, with age, an increasing number of factors, including other genes, come into play, thereby masking specific effects of the limited number of genes studied here. Clearly, a longitudinal design would have advantages for explicating differences between middle-aged and old participants.

With respect to the exploratory morphometric analysis, we found mixed results concerning the effects of APOE and CHRNA4 on the relation of age to total cortical and white matter volume. We found no genetic effects on cortical volume, but our procedure did not allow for regional analysis. Given the importance of regionally specific cortical areas for attentional function (Corbetta et al., 2000; Posner \& Petersen, 1990), genetic effects on regional cortical structural integrity would be of obvious interest. We are currently working on such an analysis in our laboratory. Individuals with the APOE- $\varepsilon 4$ allele in combination with a CHRNA4 TT genotype had significantly lower white matter volumes than the other three genotype groups. However, this association was closely linked with age. Our ability to disentangle independent contributions to interactive effects at this level was hampered by lowered power due to having MRI scans for only 97 participants.

White matter volume appeared to have effects on overall RT in the visuospatial attention task that were independent of age. The $\varepsilon 4 / \mathrm{TT}$ group with lower white matter volume also had slower RTs, thus confirming a consistent pattern of significant behavioral and anatomical traits for this group. MRI studies using a larger age range have indicated that white matter volume decreases in adults over the age of about 50 years (Bartzokis et al., 2003; Walhovd et al., 2005). Such changes are associated with age-related slowing, but our results indicate that the important factor is not chronological age per se as much as the integrity and amount of white matter. Such a result is not unexpected given the high heritability of white matter volume (Posthuma et al., 2002). White matter changes with aging probably reflect a complex set of factors, including most significantly neural factors (e.g., axonal changes; Peters, 2002) and myelin breakdown (Bartzokis, 2004). Of course, the cross-sectional design and relatively small age range examined in the present study (46-75 years) may 
have prevented us from finding independent age effects. The specific genes contributing to this heritability are not known, but given the role of APOE in lipid delivery in the brain, it is possible that APOE is one important gene. Consistent with this view, the association in the present study between APOE and overall RT in the visuospatial attention task was found to be partially mediated by white matter volume. On the basis of previous research, we had hypothesized that, of the different people we examined, those who were both APOE- $\varepsilon 4$ carriers and had the CHRNA4 TT genotype would be the most disadvantaged. Consistent with this view, we found that the participants with APOE- $\varepsilon 4 / C H R N A 4$ TT genotypes showed both lower white matter volume and slower overall RT on the attention task.

In conclusion, this study provides a replication and independent confirmation of the negative effect of the APOE- $\varepsilon 4$ allele on attentional function, both on overall RT and, more specifically, on attentional reorienting after invalid cuing. It also extends those findings to show interaction of effects of APOE with the cholinergic receptor gene CHRNA4. The reported interaction of a neural repair gene (APOE) and a neurotransmission gene (CHRNA4) in modulating behavioral effects is a novel finding but is consistent with the overlapping effects of these genes previously reported in separate studies. The MRI-derived morphometric data on a subsample indicate that reduced white matter volume may be a link through which genetic effects on time-sensitive attention functions may be mediated. Although not predicted in advance, these results will be important in guiding subsequent research with tasks anchored in validated neurocognitive models and imaging methods such as diffusion tensor imaging with higher white matter structural specificity.

\section{REFERENCES}

Alkondon, M., Pereira, E. F., Eisenberg, H. M., \& Albuquerque, E. X. (2000). Nicotinic receptor activation in human cerebral cortical interneurons: A mechanism for inhibition and disinhibition of neuronal networks. Journal of Neuroscience, 20, 66-75.

BARON, R. M., \& KenNy, D. A. (1986). The moderator-mediator variable distinction in social psychological research: Conceptual, strategic, and statistical considerations. Journal of Personality \& Social Psychology, 51, 1173-1182.

Bartus, R. T., Dean, R. L., III, Beer, B., \& Lippa, A. S. (1982). The cholinergic hypothesis of geriatric memory dysfunction. Science, 217, 408-414.

BARTzOKIs, G. (2004). Age-related myelin breakdown: A developmental model of cognitive decline and Alzheimer's disease. Neurobiology of Aging, 25, 5-18.

Bartzokis, G., Cummings, J. L., Sultzer, D., Henderson, V. W., NuechTERLEIN, K. H., \& MiNTZ, J. (2003). White matter structural integrity in healthy aging adults and patients with Alzheimer disease: A magnetic resonance imaging study. Archives of Neurology, 60, 393-398.

Bentley, P., Husain, M., \& Dolan, R. J. (2004). Effects of cholinergic enhancement on visual stimulation, spatial attention, and spatial working memory. Neuron, 41, 969-982.

Bondi, M. W., Salmon, D. P., Galasko, D., Thomas, R. G., \& Thal, L. J. (1999). Neuropsychological function and apolipoprotein E genotype in the preclinical detection of Alzheimer's disease. Psychology \& Aging, 14, 295-303.

Bondi, M. W., Salmon, D. P., Monsch, A. U., Galasko, D., ButTERS, N., Klauber, M. R., ET AL. (1995). Episodic memory changes are associated with the APOE-epsilon 4 allele in nondemented older adults. Neurology, 45, 2203-2206.

BUCKNER, R. L. (2005). Three principles for cognitive aging research: Multiple causes and sequelae, variance in expression and response, and the need for integrative theory. In R. Cabeza, L. Nyberg, \& D. C. Park (Eds.), Cognitive neuroscience of aging: Linking cognitive and cerebral aging (pp. 267-285). New York: Oxford University Press.

Cabeza, R., Nyberg, L., \& PARK, D. C. (Eds.) (2005). Cognitive neuroscience of aging: Linking cognitive and cerebral aging. New York: Oxford University Press.

Christensen, K., Gaist, D., Vaupel, J. W., \& McGue, M. (2002). Genetic contribution to rate of change in functional abilities among Danish twins aged 75 years or more. American Journal of Epidemiology, 155, 132-139.

Cohen, R. M., Podruchny, T. A., Bokde, A. L., Carson, R. E., Herscovitch, P., Kiesewetter, D. O., et AL. (2003). Higher in vivo muscarinic-2 receptor distribution volumes in aging subjects with an apolipoprotein E $\varepsilon 4$ allele. Synapse, 49, 150-156.

Corbetta, M., Kincade, J. M., Ollinger, J. M., McAvoy, M. P., \& Shulman, G. L. (2000). Voluntary attention is dissociated from target detection in the human posterior parietal cortex. Nature Neuroscience, 3, 292-297.

Corder, E. H., Saunders, A. M., Strittmatter, W. J., Schmechel, D. E., Gaskell, P. C., Small, G. W., et al. (1993). Gene dose of apolipoprotein E type 4 allele and the risk of Alzheimer's disease in late onset families. Science, 261, 921-923.

Dale, A. M., Fischl, B., \& Sereno, M. I. (1999). Cortical surfacebased analysis: I. Segmentation and surface reconstruction. NeuroImage, 9, 179-194.

Dale, A. M., \& Sereno, M. I. (1993). Improved localization of cortical activity by combining EEG and MEG with MRI cortical surface reconstruction: A linear approach. Journal of Cognitive Neuroscience, 5, 162-176

DAVIDSON, M. C., \& MARrocco, R. T. (2000). Local infusion of scopolamine into intraparietal cortex alters covert orienting in rhesus monkeys. Journal of Neurophysiology, 83, 1536-1549.

Delis, D. C., Kramer, J. H., Kaplan, D., \& Ober, B. A. (2000). California verbal learning test (2nd ed.). San Antonio, TX: Psychological Corp.

Dobbs, A. R., \& Rule, B. G. (1989). Adult age differences in working memory. Psychology \& Aging, 4, 500-503.

Driscoll, I., McDaniel, M. A., \& GuYnN, M. J. (2005). Apolipoprotein E and prospective memory in normally aging adults. Neuropsychology, 19, 28-34.

Dubelaar, E. J., Verwer, R. W., Hofman, M. A., Van Heerikhuize, J. J., Ravid, R., SwaAb, D. E., ET AL. (2004). ApoE epsilon4 genotype is accompanied by lower metabolic activity in nucleus basalis of Meynert neurons in Alzheimer patients and controls as indicated by the size of the Golgi apparatus. Journal of Neuropathology \& Experimental Neurology, 63, 159-169.

Fazekas, F., Strasser-Fuchs, S., Kollegger, H., Berger, T., Kristoferitsch, W., Schmidt, H., ET AL. (2001). Apolipoprotein E epsilon 4 is associated with rapid progression of multiple sclerosis. Neurology, 57, 853-857.

Fischl, B., Sereno, M. I., \& Dale, A. M. (1999). Cortical surfacebased analysis: II. Inflation, flattening, and a surface-based coordinate system. Neurolmage, 9, 195-207.

Flores, C. M., DeCamp, R. M., Kilo, S., Rogers, S. W., \& HarGREAVES, K. M. (1996). Neuronal nicotinic receptor expression in sensory neurons of the rat trigeminal ganglion: Demonstration of alpha3beta4, a novel subtype in the mammalian nervous system. Journal of Neuroscience, 16, 7892-7901.

Flory, J. D., Manuck, S. B., Ferrell, R. E., Ryan, C. M., \& MulDoON, M. F. (2000). Memory performance and the apolipoprotein E polymorphism in a community sample of middle-aged adults. American Journal of Medical Genetics, 96, 707-711.

Freedman, R., Coon, H., Myles-Worsley, M., Orr-Urtreger, A., Olincy, A., DAVIS, A., ET AL. (1997). Linkage of a neurophysiological deficit in schizophrenia to a chromosome 15 locus. Proceedings of the National Academy of Sciences, 94, 587-592.

GERDES, L. U. (2003). The common polymorphism of apolipoprotein E: Geographical aspects and new pathophysiological relations. Clinical Chemistry \& Laboratory Medicine, 41, 628-631. 
Greenwood, P. M., Fossella, J. A., \& Parasuraman, R. (2005). Specificity of the effect of a nicotinic receptor polymorphism on individual differences in visuospatial attention. Journal of Cognitive Neuroscience, 17, 1611-1620.

Greenwood, P. M., Lambert, C., Sunderland, T., \& Parasuraman, R. (2005). Effects of apolipoprotein $\mathrm{E}$ genotype on spatial attention, working memory, and their interaction in healthy, middle-aged adults: Results from the National Institute of Mental Health's BIOCARD study. Neuropsychology, 19, 199-211.

GreEnwood, P. M., \& PARASURAMAN, R. (2003). Normal genetic variation, cognition, and aging. Behavioral \& Cognitive Neuroscience Reviews, 2, 278-306.

Greenwood, P. M., Sunderland, T., Friz, J., \& Parasuraman, R. (2000). Genetics and visual attention: Selective deficits in healthy adult carriers of the E4 allele of the apolipoprotein E gene. Proceedings of the National Academy of Sciences, 97, 11661-11666.

KleIN, R. C., \& YAKeL, J. L. (2004). Inhibition of nicotinic acetylcholine receptors by apolipoprotein E-derived peptides in rat hippocampal slices. Neuroscience, 127, 563-567.

LeVIN, E. D., \& Simon, B. B. (1998). Nicotinic acetylcholine involvement in cognitive function in animals. Psychopharmacology, 138, 217-230

Levy, J. A., Parasuraman, R., Greenwood, P. M., Dukoff, R., \& Sunderland, T. (2000). Acetylcholine affects the spatial distribution of attention: Evidence from Alzheimer's disease. Neuropsychology, 14, 288-298.

Martin-Ruiz, C. M., Court, J. A., Molnar, E., Lee, M., Gotti, C., Mamalaki, A., ET AL. (1999). Alpha4 but not alpha3 and alpha7 nicotinic acetylcholine receptor subunits are lost from the temporal cortex in Alzheimer's disease. Journal of Neurochemistry, 73, 1635-1640.

Mauch, D. H., Nägler, K., Schumacher, S., Göritz, C., Müller, E.-C., Otто, A., ET AL. (2001). CNS synaptogenesis promoted by glia-derived cholesterol. Science, 294, 1354-1357.

McClearn, G. E., Johansson, B., Berg, S., Pedersen, N. L., Ahern, F., \& Petrill, S. A. (1997). Substantial genetic influence on cognitive abilities in twins 80 or more years old. Science, $\mathbf{2 7 6}$, 1560-1563.

Mentis, M. J., Sunderland, T., Lai, J., Connolly, C., Krasuski, J., LEvine, B., ET AL. (2001). Muscarinic versus nicotinic modulation of a visual task: A PET study using drug probes. Neuropsychopharmacology, 25, 555-564.

NoRDBERG, A. (2001). Nicotinic receptor abnormalities of Alzheimer's disease: Therapeutic implications. Biological Psychiatry, 49, 200210.

O'Brien, J. T., Erkinjuntti, T., Reisberg, B., Roman, G., Sawada, T., PANTONI, L., ET AL. (2003). Vascular cognitive impairment. Lancet Neurology, 2, 89-98.

Parasuraman, R., Greenwood, P. M., Haxby, J. V., \& Grady, C. L. (1992). Visuospatial attention in dementia of the Alzheimer type. Brain, 115, 711-733.

Parasuraman, R., Greenwood, P. M., Kumar, R., \& Fossella, J. (2005). Beyond heritability: Neurotransmitter genes differentially modulate visuospatial attention and working memory. Psychological Science, 16, 200-207.

Parasuraman, R., Greenwood, P. M., \& Sunderland, T. (2002). The apolipoprotein E gene, attention, and brain function. Neuropsychology, 16, 254-274.

Peters, A. (2002). Structural changes that occur during normal aging of primate cerebral hemispheres. Neuroscience \& Biobehavioral Reviews, 26, 733-741.

Phillips, J. M., McAlonan, K., RobB, W. G., \& Brown, V. J. (2000). Cholinergic neurotransmission influences covert orientation of visuospatial attention in the rat. Psychopharmacology, 150, 112-116.

Plassman, B. L., Welsh-Bohmer, K. A., Bigler, E. D., Johnson, S. C., Anderson, C. V., Helms, M. J., et AL. (1997). Apolipoprotein E $\varepsilon 4$ allele and hippocampal volume in twins with normal cognition. Neurology, 48, 985-989.

Plomin, R., DeFries, J. C., McClearn, G. E., \& McGuffin, P. (2001). Behavioral genetics (4th ed.). New York: Worth.

PoIRIER, J. (2000). Apolipoprotein E and Alzheimer's disease: A role in amyloid catabolism. Annals of the New York Academy of Sciences, 924, 81-90.
Posner, M. I. (1980). Orienting of attention. Quarterly Journal of Experimental Psychology, 32, 3-25.

Posner, M. I., \& Petersen, S. E. (1990). The attention system of the human brain. Annual Review of Neuroscience, 13, 25-42.

Posthuma, D., De Geus, E. J. C., Baaré, W. F. C., Hulshoff Pol, H. E., Kahn, R. S., \& Boomsma, D. I. (2002). The association between brain volume and intelligence is of genetic origin. Nature Neuroscience, $\mathbf{5}, 83-84$

Raz, N., Lindenberger, U., Rodrigue, K. M., Kennedy, K. M., Head, D., Williamson, A., ET Al. (2005). Regional brain changes in aging healthy adults: General trends, individual differences and modifiers. Cerebral Cortex, 15, 1676-1689.

Reiman, E. M., Caselli, R. J., Yun, L. S., Chen, K., Bandy, D., Minoshima, S., ET AL. (1996). Preclinical evidence of Alzheimer's disease in persons homozygous for the epsilon 4 allele for apolipoprotein E. New England Journal of Medicine, 334, 752-758.

Reiman, E. M., Chen, K., Alexander, G. E., Caselli, R. J., Bandy, D., OsBoRne, D., ET AL. (2004). Functional brain abnormalities in young adults at genetic risk for late-onset Alzheimer's dementia. Proceedings of the National Academy of Sciences, 101, 284-289.

Reinvang, I., EsPeseth, T., \& GJerstad, L. (2005). Cognitive ERPs are related to ApoE allelic variation in mildly cognitively impaired patients. Neuroscience Letters, 382, 346-351.

Resnick, S. M., Pham, D. L., Kraut, M. A., Zonderman, A. B., \& DAVATZIKos, C. (2003). Longitudinal magnetic resonance imaging studies of older adults: A shrinking brain. Journal of Neuroscience, 23, 3295-3301.

Rocca, W. A., Hofman, A., Brayne, C., Breteler, M. M., Clarke, M., Copeland, J. R., ET AL. (1991). Frequency and distribution of Alzheimer's disease in Europe: A collaborative study of 1980-1990 prevalence findings. The EURODEM-Prevalence Research Group. Annals of Neurology, 30, 381-390.

Rogers, S. W., Gahring, L. C., Collins, A. C., \& Marks, M. (1998). Age-related changes in neuronal nicotinic acetylcholine receptor subunit alpha4 expression are modified by long-term nicotine administration. Journal of Neuroscience, 18, 4825-4832.

Rosen, V. M., Bergeson, J. L., Putnam, K., Harwell, A., \& SunderLAND, T. (2002). Working memory and apolipoprotein E: What's the connection? Neuropsychologia, 40, 2226-2233.

Salthouse, T. A. (1996). The processing-speed theory of adult age differences in cognition. Psychological Review, 103, 403-428.

SARTER, M., \& Bruno, J. P. (2004). Developmental origins of the agerelated decline in cortical cholinergic function and associated cognitive abilities. Neurobiology of Aging, 25, 1127-1139.

Schmand, B., Smit, J., Lindeboom, J., Smits, C., Hooijer, C., JONKER, C., ET AL. (1997). Low education is a genuine risk factor for accelerated memory decline and dementia. Journal of Clinical Epidemiology, 50, 1025-1033.

Schneider, W., Eschman, A., \& Zuccolotto, A. (2002a). E-Prime reference guide. Pittsburgh: Psychology Software Tools.

Schneider, W., Eschman, A., \& Zuccolotto, A. (2002b). E-Prime user's guide. Pittsburgh: Psychology Software Tools.

Small, B. J., Rosnick, C. B., Fratiglioni, L., \& Bäckman, L. (2004). Apolipoprotein E and cognitive performance: A meta-analysis. Psychology \& Aging, 19, 592-600.

Snowdon, D. A., Kemper, S. J., Mortimer, J. A., Greiner, L. H., Wekstein, D. R., \& Markesbery, W. R. (1996). Linguistic ability in early life and cognitive function and Alzheimer's disease in late life: Findings from the Nun study. Journal of the American Medical Association, 275, 528-532.

Spreen, O., \& STrauss, E. (1998). A compendium of neuropsychological tests: Administration, norms, and commentary (2nd ed.). New York: Oxford University Press.

Steinlein, O. K., Deckert, J., Nothen, M. M., Franke, P., Maier, W., BeckMANN, H., ET AL. (1997). Neuronal nicotinic acetylcholine receptor alpha 4 subunit (CHRNA4) and panic disorder: An association study. American Journal of Medical Genetics, 74, 199-201.

Sundstrom, A., Marklund, P., Nilsson, L. G., Cruts, M., AdolfsSON, R., VAN BROECKHOVEN, C., ET AL. (2004). APOE influences on neuropsychological function after mild head injury: Within-person comparisons. Neurology, 62, 1963-1966.

TANZI, R. E., \& BERTRAM, L. (2005). Twenty years of the Alzheimer's 
disease amyloid hypothesis: A genetic perspective. Cell, 120, 545555 .

Teter, B., \& Finch, C. E. (2004). Caliban's heritance and the genetics of neuronal aging. Trends in Neurosciences, 27, 627-632.

Teter, B., Xu, P. T., Gilbert, J. R., Roses, A. D., Galasko, D., \& Cole, G. M. (2002). Defective neuronal sprouting by human apolipoprotein E4 is a gain-of-negative function. Journal of Neuroscience Research, 68, 331-336.

Thiel, C. M., Zilles, K., \& FinK, G. R. (2005). Nicotine modulates reorienting of visuospatial attention and neural activity in human parietal cortex. Neuropsychopharmacology, 30, 810-820.

Voytko, M. L., Olton, S., Richardson, R. T., Gorman, L. K., Tobin, J. R., \& Price, D. L. (1994). Basal forebrain lesions in monkeys disrupt attention but not learning and memory. Journal of Neuroscience, 14, 167-186.
Walhovd, K. B., Fuell, A. M., Reinvang, I., Lundervold, A., Dale, A. M., EilerTSEn, D. E., ET AL. (2005). Effects of age on volumes of cortex, white matter and subcortical structures. Neurobiology of Aging, 26, 1261-1270.

WECHSLER, D. (1999). Wechsler abbreviated scale of intelligence. San Antonio, TX: Psychological Corp.

Whalley, L. J., Starr, J. M., Athawes, R., Hunter, D., Pattie, A., \& Deary, I. J. (2000). Childhood mental ability and dementia. Neurology, 55, 1455-1459.

Witte, E. A., Davidson, M. C., \& Marrocco, R. T. (1997). Effects of altering brain cholinergic activity on covert orienting of attention: Comparison of monkey and human performance. Psychopharmacology, 132, 324-334.

Xiang, Z., Huguenard, J. R., \& Prince, D. A. (1998). Cholinergic switching within neocortical inhibitory networks. Science, 281, 985-988. 